\title{
Avaliação do estudante com deficiência intelectual: acompanhamento do processo de aprendizagem ou legitimação de aprovação automática
}

\section{Assessment of students with intellectual disabilities: monitoring of the learning process or legitimation of automatic approval}

\author{
Rosiney Vaz de Melo Almeida ${ }^{1 *}$, Dulcéria Tartuci $1^{2}$
}

\begin{abstract}
RESUMO
Este artigo objetiva analisar o processo de avaliação de estudantes com deficiência intelectual matriculados no ensino regular, na sala de aula comum, com vista a efetivação da aprendizagem inclusiva destes estudantes. É parte de uma pesquisa em mestrado, cujo escopo é a construção de conhecimento e o letramento ancorado na perspectiva histórico-cultural que alicerça as discussões dos dados produzidos que apontam para uma realidade em que o processo de avaliação efetivamente não contempla e não evidencia o nível real de aprendizagem dos estudantes como deficiência e não é visto como diagnóstico necessário à construção de caminhos a serem trilhados em favor do desenvolvimento acadêmico que supere conceitos de não aprendizagem valorizando a socialização como desenvolvimento do estudante com deficiência.
\end{abstract}

Palavras-chave: Avaliação; Aprendizagem; Construção de Conhecimento; Deficiência Intelectual.

\begin{abstract}
This objective analyze the process of evaluation in the students with Intellectual disability enrolled in regular education, in the common classroom, with a view to effective inclusive learning this students. Is part of master's research, whose scope is construction of knowledge and the literacy anchored in the perspective history-culture, that foundation the discourses of the data produced that point to a reality in which the evaluation process effectively no contemplate and no evidence the real level of learning of the students as deficiency. No seen as a necessary diagnosis for the construction of ways to be trodden in favor of academic development to overcome concepts of non-learning, valuing socialization as a development of the disabled student.
\end{abstract}

Keywords: Evaluation; Learning; Knowledge Building; Intellectual Disability.

\section{INTRODUÇÃOO}

\footnotetext{
${ }^{1}$ Secretaria Estadual de Educação de Goiás 1.

*E-mail: rosiney_06@hotmail.com

${ }^{2}$ Programa de Pós-Graduação em Educação - Universidade Federal de Catalão. E-mail: dutartuci@gmail.com
} 
Este artigo $^{\mathrm{i}}$ tem por objetivo promover uma reflexão sobre o processo de avaliação de estudantes com deficiência intelectual matriculados no ensino regular, na sala de aula comum, com vista a efetivação da aprendizagem inclusiva deste destes estudantes.

Como parte de um trabalho de pesquisa de mestrado, é pertinente salientar o processo metodológico que deu origem a este artigo. A pesquisa em questão foi realizada no ano de 2014 a 2015 em duas escolas públicas que atendiam aos requisitos de: terem estudantes com deficiência intelectual, com laudo, matriculados em sala de aula comum, receberem suporte de professor de apoio à inclusão na sala de aula comum e professor de atendimento educacional especializado atendendo na sala de recursos multifuncionais. Fizeram parte da pesquisa original cinco professores regentes, cinco professores de apoio à inclusão, dois professores de atendimento educacional especializado e quatorze estudantes com diagnóstico de deficiência intelectual. Os dados foram produzidos a partir de três instrumentos: observação participante, entrevista com grupo focal e análise de documentos. Os dados interpretados a luz da epistemologia histórico-cultural que fundamenta o trabalho de mestrado, em questão.

A análise dos dados possibilitou a discussão de vários aspectos relacionados à escolarização de estudantes com deficiência intelectual, na etapa do ensino fundamental I, tendo como escopo o letramento e a construção de conhecimento por parte deste alunado. A avaliação da aprendizagem foi um dos aspectos abordados e neste artigo é o tema central da discussão que perpassa aspectos relacionados à legislação pertinente, ao processo de compreensão das possibilidades de desenvolvimento da criança com deficiência intelectual e do preparo dos agentes educacionais para lidar com o processo avaliativo no ambiente escolar.

\section{AVALIAÇÃO DA APRENDIZAGEM DO ESTUDANTE COM DEFICIÊNCIA INTELECTUAL NUMA PERSPECTIVA INCLUSIVA}

Ao propor uma reflexão sobre a avaliação educacional de estudantes com deficiência intelectual em uma perspectiva inclusa, faz-se necessário o entendimento sobre o que vem a ser este processo. Em uma entrevista, ao ser questionado sobre a predominância de novas formas de avaliação em relação à aplicação de provas tradicionais, Luckesi (2004) afirma que o essencial é a compreensão que se tem em 
relação ao que as provas tradicionais significam e o que é avaliação. Para ele, as provas fazem parte de um contexto classificatório ao passo que avaliar significa

subsidiar a construção do melhor resultado possível e não pura e simplesmente aprovar ou reprovar alguma coisa. Os exames, através das provas, engessam a aprendizagem; a avaliação a constrói fluidamente. (LUCKESI, 2004, p. 4)

$\mathrm{O}$ autor pontua que o processo avaliativo, ao contrário do exame que visa à classificação, supõe um rigoroso acompanhamento e a reorientação das atividades tendo em vista resultados bem sucedidos. Salienta que ao final de um período avaliativo, o professor estará subsidiado para mensurar a aprendizagem real de seu estudante, analisar os dados coletados por meio dos instrumentos utilizados para este fim e tomar decisões assertivas sobre melhores estratégias para envolver todos. Ninguém deve ficar para trás.

No compasso desta discussão a Resolução $N^{o}$ 07/2006 do estado onde se localizam as escolas campo da pesquisa, em sua seção III, trata a questão ressaltando que a avaliação deve estar pautada nas potencialidades e possibilidades do estudante, mantendo um caráter consubstanciado e diagnóstico do processo de atendimento educacional com vista da aprendizagem aos estudantes com deficiência. Nesta categoria, a avaliação será tomada como foco da discussão por estar presente nos discursos dos professores alimentando a prática educativa no que concerne ao atendimento de seus estudantes com deficiência intelectual.

Os dados referentes à avaliação, apresentados a seguir, fazem parte da entrevista com o grupo focal, da observação participante e da análise dos registros em instrumentos próprios das escolas pesquisadas, e foram analisados tendo como parâmetro de análise a Resolução citada acima e a epistemologia histórico-cultural que fundamenta a pesquisa de mestrado que deu origem a este artigo.

Dentre os instrumentos utilizados pelas escolas como forma de sistematização do processo de avaliação fazem parte do corpus de análise desta pesquisa a:

1. Ata de Resultados finais - contém o resultado final das turmas observadas; a avaliação é mensurada em notas de 0.0 a 10.0; e a média mínima para aprovação é 5.0 pontos;

2. Proposta de Avaliação para a Diversidade (PAD): é um instrumento criado pela Seduce É um relatório descritivo da avaliação do estudante com deficiência. Nele é apontado o desenvolvimento do estudante em dois eixos: a) dados gerais - destinados à identificação do estudante; b) dados relevantes sobre o estudante - nestes são avaliados a 
história de vida do estudante e o conteúdo acadêmico em sete aspectos: atenção e concentração; nível de abstração; criatividade; participação nas atividades escolares; envolvimento com os colegas; com o professor e envolvimento dos pais.

3. Avaliação diagnóstica: é um documento gerado pelo SIGE de cada escola e apresenta os resultados da Avaliação Diagnóstica, mecanismo externo do Governo Estadual, que tem por objetivo diagnosticar o nível de aprendizagem dos estudantes a partir das habilidades propostas para cada turma nas áreas de Língua Portuguesa, Matemática, Produção de Texto e Ciências. Em 2014 aconteceu em três momentos, no primeiro, segundo e terceiro bimestres.

4. Avaliação Nacional de Alfabetização: aplicada no final do terceiro bimestre aos estudantes do terceiro ano, final do ciclo de alfabetização. Os resultados apresentados até então são preliminares.

Estes instrumentos foram selecionados por estarem sistematizados na rotina das escola pesquisadas e possibilitarem a construção de sentidos sobre o modo como a avaliação é vivenciada nesses campos educativos. Alimentando as práticas educativas e os discursos que apontam o desenvolvimento e a aprendizagem dos estudantes com deficiência, refletem a proposta política e pedagógica das escolas.

Por meio da observação participante, a avaliação aponta para uma realidade em que os estudantes com deficiência intelectual têm seu processo de desenvolvimento avaliado por princípios negativos, construídos historicamente e versam sobre as impossibilidades de aprendizagem dos conteúdos acadêmicos que constituem a matriz curricular da escola comum, por estes estudantes, evidenciando a inexistência de um projeto de avaliação que considere o desenvolvimento real e potencial do estudante com deficiência intelectual.

Nota-se que os estudantes com deficiência intelectual, em ambas as escolas, apresentam uma defasagem de aprendizagem em relação aos estudantes que compõem as turmas em que estão matriculados, que deve ser considerada no processo de avaliação geral das escolas. Dos quatorze estudantes, participantes desta pesquisa, nenhum lê ou escreve com fluência ou realiza as operações de aritmética com autonomia, embora demonstrem em vários momentos indícios de construção de conhecimento destas habilidades. E nas salas de aulas, suas atividades são flexibilizadas em níveis reduzidos e, nos casos mais graves, ficam a maior parte do tempo ociosos. O maior desenvolvimento alcançado está relacionado às práticas de interação social destes estudantes, em vista de 
um ensino tradicional cujos pressupostos estão voltados para o desenvolvimento do processo de sociabilização dos estudantes com deficiência, resquício da educação especial, presente nas escolas pesquisadas que apresentam um contexto inclusivo.

Culturalmente e historicamente a educação da criança com deficiência esteve pautada no que faltava, em aspectos negativos do seu desenvolvimento. A PAD, relatório descritivo para avaliar a aprendizagem dos estudantes com deficiência, traz como pontos de avaliação da aprendizagem o desenvolvimento das funções psicológicas superiores e que estão diretamente relacionadas às limitações das crianças com deficiência intelectual, como a capacidade de concentração, de abstração, de generalização e de convivência social.

Ao analisar os registros dos professores neste documento em quatro turmas, todos os estudantes foram avaliados negativamente no desenvolvimento destas funções, que foram consideradas nulas ou muito limitadas, o que lhes impossibilita a aprendizagem e a evolução, conforme o registro feito sobre o estudante Ruan, em que a palavra nula aparece relacionada a todas funções avaliadas, conforme registro que segue:

Doc 5 - Nível de abstração: Seu nível de abstração é praticamente nulo. Atenção e concentração: $O$ aluno não tem atenção e sua concentração nas atividades propostas é quase nula.

Criatividade: Sua criatividade é praticamente nula. (PAD - $3^{\circ}$ ano ESP)

Neste relatório, apenas as professoras do $4^{\circ}$ ano evidenciaram o desenvolvimento real de seus estudantes, registrando o ponto em que houve aprendizagem, como no registro sobre a aluna Ana:

Doc 6 - Nível de abstração: Seu nível de abstração evoluiu bastante do primeiro semestre até hoje. A aluna consegue efetuar cálculos sem ajuda do material concreto e dá respostas mais elaboradas.

Nível de Generalização: Percebe-se que vem evoluindo aos poucos devido a sua grande dificuldade de retenção da aprendizagem. Criatividade: A aluna realiza suas atividades com intervenções da professora de apoio à inclusão, é capaz de realizar problemas de simples resolução de forma convencional. $\left(\mathrm{PAD}-4^{\circ}\right.$ ano $\left.\mathrm{ESV}\right)$

Este instrumento (PAD) representa uma renovação na prática pedagógica de avaliação do estudante com deficiência, e, no caso específico deste artigo, aquele com deficiência intelectual, pois possibilita uma análise do processo de construção de conhecimento que supera a rotulação imposta pelos laudos, pelos valores estigmatizantes 
construídos, histórica e culturalmente, em favor de uma avaliação com bases qualitativas, por meio das quais é possível identificar a formação de conceitos científicos por estas crianças, reconhecer o avanço nos aspectos da linguagem, e entender como cada uma aprende.

Diante deste enunciado se torna necessária uma discussão sobre o seu aproveitamento na avaliação efetiva do estudante com deficiência intelectual, uma vez que o referido instrumento não é considerado no momento de mensurar quantitativamente o aprendizado da criança e nem pesa na decisão sobre sua aprovação ou reprovação. E o estudante com deficiência intelectual, que necessita de apoio para desenvolver suas atividades, conforme o relatado é submetido ao processo tradicional de avaliação sem nenhuma adequação ou flexibilização, como a experiência vivenciada na turma do primeiro ano, e registrada no Episódio 17 em que a pesquisadora aponta:

Episódio 17 - Avaliação de Língua Portuguesa. Todos os estudantes receberam a avaliação, inclusive a Marina (estudante com síndrome de down). A prova foi direcionada pela professora regente que leu oralmente questão por questão e explicou o que fazer em cada uma delas. No início da avaliação a profissional de apoio à inclusão não estava na sala, retornou após alguns momentos, circulou pela sala e auxiliou algumas crianças. A aluna Marina ficou o tempo todo sem acompanhamento da professora regente ou da professora de apoio à inclusão para mediarem a ação dela no intuito de ajudá-la a resolver a questões da prova. O comportamento da aluna foi semelhante ao dos demais estudantes. Ao receber a prova, procurou pelo estojo, mas não o encontrou. Neste momento, a professora de apoio à inclusão, tendo entrado na sala, percebe seu desejo e pega o estojo dela que estava no armário e entrega a ela explicando que naquele dia nem lápis ela havia levado. Marina pega, do estojo, um lápis qualquer e começa a rabiscar a prova, como se estivesse fazendo as atividades como os outros estudanteestudantes. Ambas professoras não se aproximaram da aluna. Após percorrer a sala de carteira em carteira a professora de apoio à inclusão sai da sala de aula. A aluna Marina estava sentada no fundo da sala, ao meu lado, percebendo seu interesse intervenho e resolvo contar para ela o texto da prova. Era uma história de uma pessoa de nome Zélia que gostava de fazer doce de goiaba e de sua neta que adorava comer os doces que a avó fazia e também ajudava a avó na limpeza da casa. Em seguida fui fazendo as perguntas da prova que ela deveria responder. Oralmente ela conseguiu responder as três questões relativas ao texto, mas não conseguiu escrever as respostas. Neste momento a professora regente se aproximou e comentou como acha difícil ter na sala uma aluna como a Marina, que não estava preparada e que não sabia o que fazer, porque a criança não sabia nada e pergunta: Ela deu conta de alguma coisa? Mostro a professora o pequeno sucesso de Marina e convido-a a contar para a tia Mery o que ela entendeu do texto.

Pesquisadora-Marina como é o nome da vovó?

Aluna Marina - Zazá.

Pesquisadora-Qual o doce que a vovó Zazá fez? 


\begin{abstract}
Aluna Marina - Goiaba.
Pesquisadora - Qual o nome da neta da vovó Zazá?

Aluna Marina - Não respondeu e se levantou.

Professora Mery PSC_Olha! Ela até dá conta de alguma coisa, né?

Mas dá muito trabalho, né?

A professora de apoio à inclusão retorna a sala neste momento e percebe a conversa entre mim e a professora regente e também comenta o quanto é difícil ensinar para uma criança daquele jeito e que o que ela sabe sobre isso foi pesquisado na Internet. ( $1^{\circ}$ ano ESP $06 / 11 / 2014)$
\end{abstract}

Em um processo de avaliação qualitativa, aspectos deste episódio seriam considerados positivos no desenvolvimento da aluna Marina. Por exemplo, o comportamento cultural da criança esboçado ao receberem a prova e pegarem os instrumentos necessários para preenchê-la e ir escrevendo seguindo as orientações da professora a cada atividade mediada de forma homogênea a toda a sala de aula, indica uma capacidade de imitação do comportamento de seus colegas por parte da aluna, ressalta um aprendizado coletivo e individualizado por ela sobre como deve ser um momento de "prova".

Ao ser capaz de oferecer algumas respostas em relação à interpretação do texto proposto, nota-se sua capacidade de trabalhar com informações que exigem certo nível de abstração, porém, como todo o processo foi mediado pelo diálogo, incluindo suas respostas, não foi considerado como válido para a avaliação.

Outro ponto a se considerar sobre a validade da PAD diz respeito a não existência destes relatórios para os estudantes do terceiro ano da Escola São Vicente, pois, estando em licença para tratamento de saúde, a professora de apoio à inclusão escolar não o preencheu e não houve outra pessoa que pudesse fazê-lo. Mediante esta situação qual é a função desta avaliação descritiva? No que ela contribui para apontar caminhos para a construção de estratégias de ensino que promovam o desenvolvimento destes estudantes, significando positivamente seu processo educativo?

Em consonância com o discurso acima, fundamentado na observação do cotidiano da sala de aula e nos dados da PAD, o instrumento de avaliação diagnóstica do $3^{\circ}$ bimestre de uma das escolas pesquisadas, conforme gráfico abaixo, traz como resultado da aprendizagem dos estudantes desta escola um percentual de acertos nas turmas em Língua Portuguesa e Matemática acima da média 5.0. No entanto, na produção escrita o índice de acerto no $3^{\circ}$ ano ficou acima da média, mas não corresponde ao apresentado como resultado da avaliação de Língua Portuguesa, que é de $89 \%$ de acertos, e no quarto ano está muito abaixo da média. 


\section{GRÁFICO 1 - Indicadores de Desempenho - Escola São Pedro}

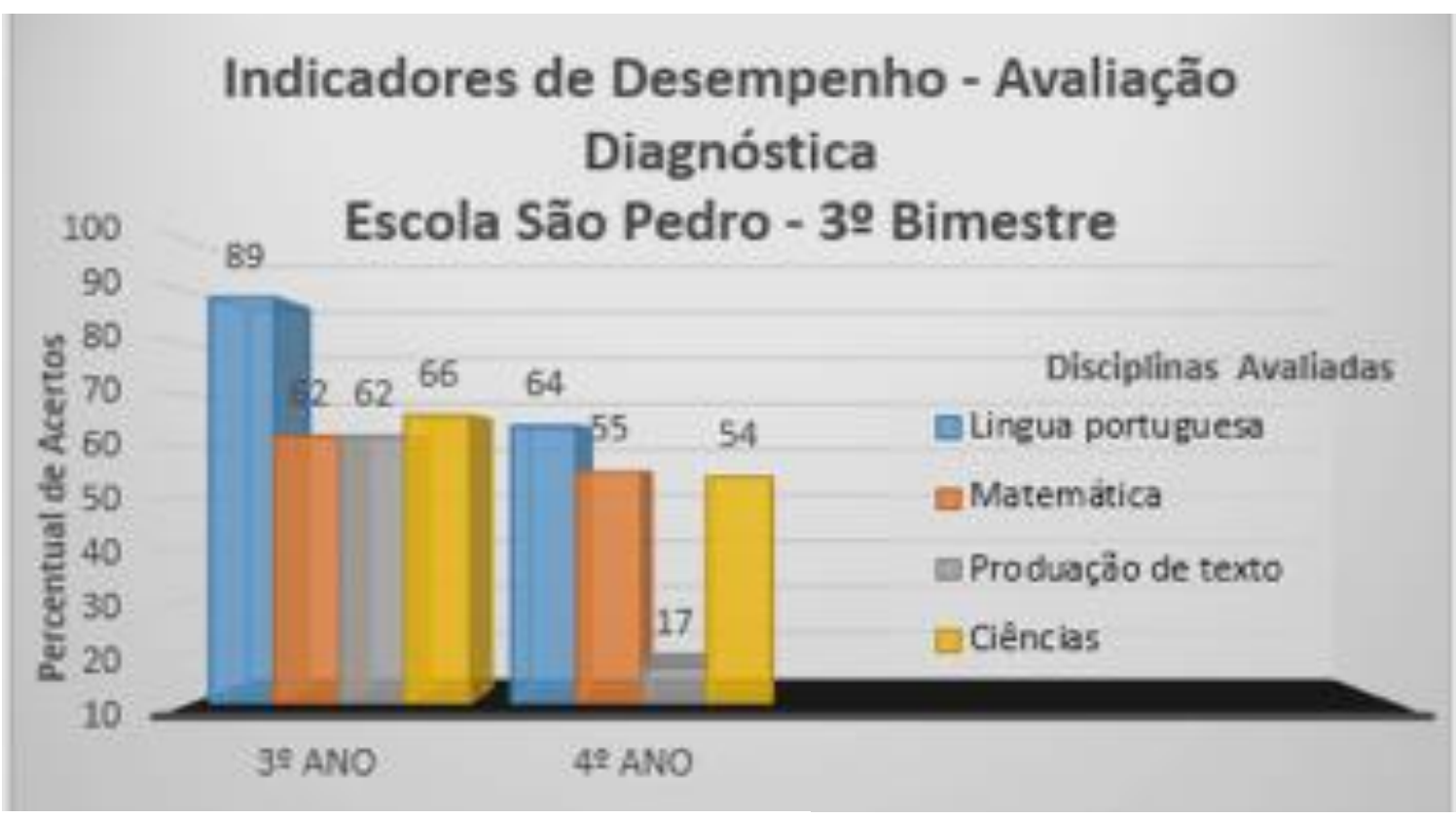

Fonte: Sige - Escola São Pedro/2015.

O que chama atenção nestes resultados é que os estudantes com deficiência não participaram da avaliação do terceiro ano; no quarto ano o estudante Welinton, com deficiência intelectual, em Língua Portuguesa e Matemática alcançou a média 6.0 e 5.0, respectivamente, porém, na produção de texto sua média foi de $1.0 \%$ de acertos, e em Ciências 1,0\% de acertos; a aluna Marina, do primeiro ano não participou, pois não há avaliação diagnóstica para esta turma. Portanto, os resultados da avaliação diagnóstica, no aspecto geral das turmas analisadas, não contempla a singularidade dos estudantes com deficiência intelectual, pois estes não participaram do processo ou individualmente ficaram muito abaixo da média de sua turma.

$\mathrm{Na}$ avaliação diagnóstica da Escola São Vicente todos os estudantes com deficiência intelectual participaram do processo avaliativo composto por provas objetivas das áreas avaliadas e escrita na produção de texto. O resultado do terceiro e quarto anos desta escola, turmas foco deste estudo, mostra uma realidade preocupante relacionada às habilidades de escrita das turmas, conforme expresso no gráfico abaixo:

\section{GRÁFICO 2 Indicadores de Desempenho - Escola São Vicente}

\section{Indicadores de Desempenho - Avaliação Diagnóstica


O gráfico mostra que o rendimento na escrita ficou abaixo da média nas duas turmas. Ao analisar o resultado por turma, em que aparecem os dados dos onze estudantes com deficiência intelectual que participaram da avaliação, em que cinco alcançaram pontuação na avaliação escrita, sendo que três ficaram acima da média e dois abaixo da média. Seis estudantes zeraram na prova de produção de texto. Este baixo rendimento também é visível nas demais disciplinas, principalmente em Matemática e Ciências e embora na avaliação em Língua Portuguesa tenham alcançado os melhores resultados, este é um dado contraditório com a ausência de habilidades na escrita, de acordo com os dados analisados.

Este contexto avaliativo remete a um questionamento sobre como o processo de avaliação em uma escola inclusiva pode colaborar para o desenvolvimento do estudante e ser significado como uma prática de ensino. A avaliação para Luckesi (2006) é diagnóstica e inclusiva e com vistas ao desenvolvimento é sempre um ato dialógico. Ressignificar a prática educativa é também pensar o modelo de avaliação baseado em resultados quantitativos que têm como objetivo classificar o estudante pelo resultado alcançado, sendo encerrado em si mesmo em favor de metodologias mais flexíveis.

Outro aspecto a ser considerando neste modelo de avaliação externa vivenciada pelas escolas pesquisados é o formato fechado da avaliação não sendo possível flexibilizar ou adapta-las para atender a realidade dos estudantes avaliados e se constituir em um processo de diagnóstico do desenvolvimento real dos estudantes com deficiência e ressalta a não construção de conhecimentos acadêmicos no formato ideal das escolas tradicionais e evidencia aspectos gerais de seu desenvolvimento, no que tange, a 
socialização como o único caminho de aprendizagem para estes estudantes conforme as vozes ouvidas no grupo focal.

Os discursos dos professores, no grupo focal, incialmente, apontam a socialização como o único aprendizado possível ao estudante com deficiência intelectual, conforme a fala da professora de apoio à inclusão Elena PAI, que afirma:

Excerto 30 - A Sandra tem experiência com um menino que tem deficiência intelectual, então ele não aprende. Ele está ali para sociabilizar. (Elena PAI) E da professora da classe comum Nívea PSC

Excerto 31 - Ele (Ruan) não gosta de aprender. Ele não, assim, ele não se interessa em querer aprender. Então eu vejo que é mesmo só a socialização que dá. (Nívea PSC)

A socialização, para Vygotski (1997), é o caminho para a compensação da deficiência. Nesse sentido, é fundamental no processo educativo da criança, para alcançar resultados que levem ao desenvolvimento das funções superiores necessita ser mediada prepositivamente. A interação pura e simples não é positiva para os estudantes com deficiência intelectual, pois neste aspecto ela acontece em qualquer ambiente, familiar, religioso ou mesmo de festa, sem causar transformações nas estruturas mentais da criança, que não está na escola só para se socializar, o que os discursos conduzem a concluir.

Os dados aqui interpretados estão atrelados a uma avaliação concebida, conforme Vygotski (1997), como um processo dinâmico e contínuo em que a prática de avaliar é inerente ao ato de planejamento do ensino e subsidia os caminhos a serem tomados no processo de ensino e aprendizagem, não se constituindo como mecanismo de classificação e atribuição de rótulos ou ainda como método de aprovação automática, o que está muito presente nos discursos no ambiente escolar e que legitima o baixo rendimento como intrínseco à própria deficiência. Estes e outros rótulos de não aprendizagem fazem parte de uma avaliação pautada no déficit, sendo historicamente construída e preservando os aspectos quantitativos em detrimento aos qualitativos. É este aspecto que o conceito multidimensional da deficiência intelectual busca superar ao considerar a pessoa e o seu contexto como parte da constituição de sua personalidade, interferindo em sua competência linguística e adaptativa, influenciando na aquisição dos conceitos científicos no contexto escolar.

De acordo com os discursos dos professores no grupo focal, a aprendizagem de seus estudantes com deficiência intelectual, no que diz respeito a estes conceitos, não é suficiente, conforme as expectativas expressas nos enunciados que seguem: 
Excerto 32 - Eu penso assim, eu gostaria que a Marina ficasse comigo no ano que vem para ver se ela se alfabetiza, mas elas querem que ela passa...Ela não escreve nada. (Mery PSC)

Excerto 33 - É porque é assim: eu espero, acho que todos nós professores esperamos tanto, queremos tanto, se cobra no final, que eu ainda acho que que deveria mais. (Otávio PSC)

Pensando neste processo de avaliação, pautado nos discursos dos professores, que não consideram o aprendizado de seus estudantes suficiente para ser entendido como construção de conhecimento, processo de aquisição do letramento, a reprovação seria uma consequência natural para eles. Esta visão negativa do processo de construção de conhecimento do estudante com deficiência intelectual é evidenciada em outra pesquisa realizada em uma escola na baixada fluminense, ao citarem que estas práticas não positivas

são comuns à educação brasileira que tradicionalmente, tem optado por realizar avaliações de maneira descontextualizada e limitadora, na qual a verificação da aprendizagem é preterida, uma vez que o dado é coletado de maneira acrítica e se encerra nele mesmo (PLETSCH; OLIVEIRA, 2014, p.130).

Discurso este que não se traduz nos documentos analisados. Na Ata de Resultados Finais observa-se que a maioria dos estudantes com deficiência intelectual, foram considerados aptos e obtiveram a média necessária para a aprovação suficiente de seus estudos. Com base nos dados das Atas de Resultados Finais este dado assim se expressa:

Doc 7 - Todos os alunos do Atendimento Educacional Especializado, da Escola São Vicente, $3^{\circ}$ e $4^{o}$ ano foram aprovados com a média próxima da mínima, entre 5.0 e 6.5. $\mathrm{Na}$ escola São Pedro, a Aluna Marina foi aprovada com a nota mínima, 5.0 em todas as disciplinas e os alunos Ruan e Welinton foram reprovados e a suas notas ficaram abaixo de 5.0. (ATA $3^{\circ}$ ano ESV).

O que estes dados dizem, realmente, do desenvolvimento dos estudantes com deficiência intelectual e como os professores orientarão o planejamento das atividades da sala de aula consiste o centro desta discussão e da ressignificação da educação geral para atender à demanda gerada pela inclusão nos últimos vinte anos.

Ancorada no direito de todos, ao acesso e permanência em uma escola que ofereça, nos dizeres de Tartuci (2011, p.1), "condições para que o estudante permaneça e vivencie um processo educacional de qualidade" e um procedimento de avaliação justo faz parte da qualidade do ensino. Quando aplicado "adequadamente [...] contribui para o 
desenvolvimento de ações e práticas curriculares que favorecem a aprendizagem dos alunos com deficiência intelectual" (PLETSCH; OLIVEIRA, 2014, p. 135). Mantém o diálogo com as propostas de ensino das escolas em suas diferentes dimensões, quer seja o planejamento, a metodologia, as estratégias de ensino ou a articulação do trabalho integrado entre educação comum e educação especial, além do ensino colaborativo entre o professor regente, o professor de apoio à inclusão e o professor de AEE.

Nota-se que ouve avanços na proposta de avaliação do estudante com deficiência, e que estas escolas possuem aparatos legais que orientam o seu fazer pedagógico enquanto escola de ensino regular que mantem uma perspectiva social inclusiva, entretanto, em conformidade com Braun (2012) estas orientações e aparatos legais ainda não atendem à demanda dos estudantes com deficiência, a autora destaca ainda a necessidade de uma mudança significativa na forma como as escolas se organizam e na realidade heterogênea que as caracterizam na atualidade, e que o processo avaliativo vivenciado não contempla por manter um caráter ideológico do estudante.

Os dados de avaliação apresentados neste artigo representam uma dada realidade, e por isso não são passíveis de generalizações, mas observa-se por meio de outras pesquisas (PLETSCH; OLIVEIRA, 2014; BRAUN, 2012; VELTRONE, 2011) situações semelhantes a esta, quando a questão é a aprendizagem efetiva do estudante com deficiência, evidenciando que as escolas de diferentes realidades apresentam a necessidade de se prepararem para lidar com a educação especial na perspectiva inclusiva e desta forma as políticas públicas que garantem os serviços e os recursos necessários ao fazer pedagógico que atenda ao público alvo da educação especial, por si só não resolve toda a emblemática que circunda o processo avaliativo da criança com deficiência inserida no bojo das escolas de ensino regular. A avaliação do estudante com deficiência, deveria possibilitar

a identificação de mudanças a serem feitas e também avaliar a necessidade de tais mudanças[...] não basta identificar que o aluno tem deficiência intelectual, mas sim, reconhecer suas habilidades e limitações [...] as necessidades educacionais do mesmo e os caminhos que tenha sucesso em seus percursos escolares (VELTRONE, 2011, p. 68).

Compreendida nesta dimensão a avaliação torna-se a orientadora de todo o fazer pedagógico e não só um instrumento de medição ou de legalização da promoção automática dos estudantes, quer sejam, com deficiência ou sem deficiência. Os dados analisados neste artigo, podem colaborar para uma reflexão crítica de diferentes 
realidades educacionais, que experimentam as mesmas angustias em relação ao ensinoaprendizagem dos estudantes com deficiência, vencendo assim o estigma de exclusão presentes na realidade da educação especial na perspectiva inclusiva.

\section{REFERÊNCIAS}

BAKHTIN, M. Marxismo e filosofia da linguagem. 13 ed. São Paulo: Hucitec, 2009.

BRAUN, Patrícia. Intervenção Colaborativa Sobre os Processos de Ensino e Aprendizagem do Aluno Com Deficiência Intelectual. 2012- 314 F. Tese (Doutorado em Educação). Universidade do Estado do Rio De Janeiro-RJ, Disponível em: http://capesdw.capes.gov.br/?login-url-success=/capesdw/ $\mathrm{e}$

em http://bdtd.ibict.br/vufind/. Acessado em out/2015.

CAMPOS, Katia Patrício Benevides. Isabel na Escola: Desafios e Perspectivas Para a Inclusão de uma Criança com Síndrome de Down Numa Classe Comum. 2012. 185 fl. Tese (Doutorado em Educação). Universidade do Estado do Rio de Janeiro. Rio de Janeiro-RJ. Disponível em: http://capesdw.capes.gov.br/?login-url-success=/capesdw/. Acessado em out $/ 2015$.

FERREIRA, Maria Cecília Carareto. A educação especial de alunos com deficiência intelectual pode se viabilizar na perspectiva do letramento. In: JESUS, Denise Meyrelles de. et al. (Org.) Inclusão práticas pedagógicas e trajetórias de pesquisa. 2 ed. Porto Alegre: Mediação, 2009. p. 101-109.

GOIÁS. Diretrizes Operacionais da Rede Público do Estado de Goiás. Disponível em: http://www.educacao.go.gov.br/documentos/diretrizes2011.pdf. Acessado em $01 / 02 / 2015$

GOIÁS. Resolução CEE N. 07, de 15 de dezembro de 2006. Disponível em: www.mp.go.gov.br/.../hp/.../res._cee_nr_07_de_15_dezembro_2006.pd. Acessado em 28/07/2015.

GOIÁS. Resolução CEE/CP N. 5, de 10 de junho de 2011. Disponível em: www.seduc.go.gov.br/.../RESOLUÇÃO\%20CEE-CP\%20N.5,\%20DE\%2 Acessado em: 20/052015.

LUCKESI, Cipriano Carlos. Considerações gerais sobre avaliação no cotidiano escolar. Entrevista concedida à Aprender a Fazer, publicada em IP - Impressão Pedagógica. Editora Gráfica Expoente, Curitiba, PR, $\mathrm{n}^{\circ}$ 36, 2004, p. 4-6. Disponível em: http://www.luckesi.com.br/artigosavaliacao.htm Acessado em: 22/07/15

LUCKESI, Cipriano Carlos. Entrevista concedida a Revista Nova Escola. 191 ed, publicada em abril, 2006. Disponível em: http:/www.revistaescola.abril.com.br. Acessada em 22/07/15. 
PLETSCH, Márcia Denise. Educação Especial e inclusão escolar: problematizando a relação entre políticas, práticas curriculares e processo de ensino aprendizagem. $2 \mathrm{~d}$, Rio de Janeiro, 2013.

PLETSCH, Márcia Denise Educação Especial E Inclusão Escolar: Políticas, Práticas Curriculares E Processos De Ensino E Aprendizagem. In: Poíesis Pedagógica, CatalãoGoiás, v.12, n.1, p. 7-26, jan/jun. 2014a. Disponível em: https://www.revistas.ufg.br/index.php/poiesis/article/viewFile/31203/16801?journal=po iesis. Acessado em: abril/2015

PLETSCH, Márcia Denise Repensando a Inclusão Escolar de Pessoas com Deficiência Mental: diretrizes políticas, currículo e práticas pedagógicas. 2 ed. rev. e ampl., Rio de Janeiro, Nau: Edur, 2014.

PLETSCH, Márcia Denise; OLIVEIRA, Mariana Corrêa Pitanga de. Políticas De Educação Inclusiva: Considerações Sobre A Avaliação Da Aprendizagem De Alunos Com Deficiência Intelectual. In: Revista Educação Arte e Inclusão Vol.10, n. 2, 2014. Disponível em: http://www.revistas.udesc.br/index.php/arteinclusao/article/view/5846. Acessado em: 20/07/15.

TARTUCI, Dulcéria. Professor de Apoio, Seu Papel e Sua Atuação na Escolarização de Estudantes com Necessidades Educacionais Especiais em Goiás. In: VII Encontro da Associação Brasileira de Pesquisadores em Educação Especial. Londrina, de 08 a 10 de novembro de 2011. Anais... Londrina, 2011.

VELTRONE, Aline Aparecida; MENDES, Enicéia Gonçalves. Impacto da Mudança de Nomenclatura de Deficiência Mental para Deficiência Intelectual. In: Rev. Educação em Perspectiva, Viçosa, v. 3, n. 2, p. 448-450, jul./dez. 2012. Disponível em: http://www.seer.ufv.br/seer/educacaoemperspectiva/index.php/ppgeufv/article/viewFile/ 235/91. Acessado em: 20/10/2015.

VYGOTSKI, Liev Semióvich. Obras Escogidas. Fundamentos da Defectologia. Tomo V. Trad. Julio Guilherme Blank. Madrid: Visor Dist. S.A., 1997.

Recebido em: 01/12/2021

Aprovado em: 23/12/2021

Publicado em: 28/12/2021

${ }^{\text {i }}$ Este artigo faz parte da pesquisa de mestrado defendida no ano de 2016, e que versa sobre a escolarização de estudantes com deficiência intelectual, em um perspectiva inclusiva. 